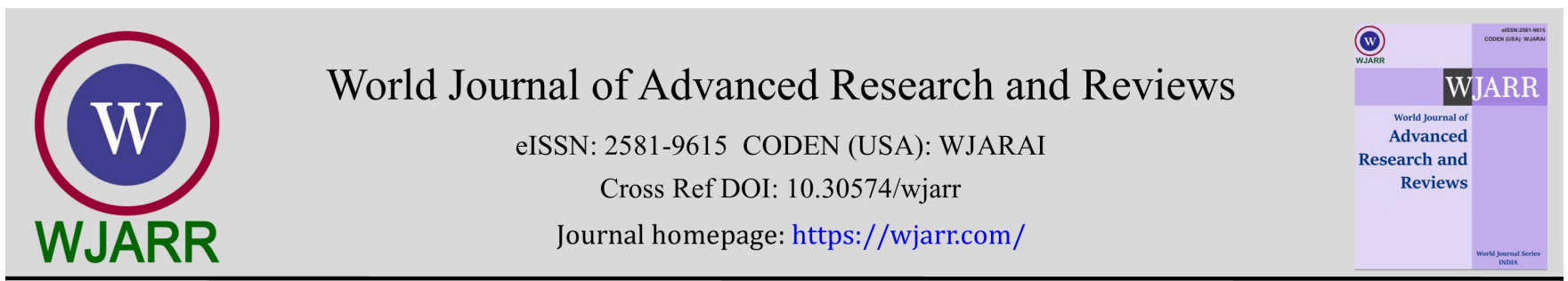

(RESEARCH ARTiClE)

Check for updates

\title{
Description of the surgical technique for repairing neglected Achilles tendon ruptures according to Bosworth
}

\author{
Omar Fadili *, Abdellah Chrak, Souhail Echchoual, Mohamed Laffani and Mustapha Fadili \\ Service de Traumatologie-Orthopédie et de Chirurgie Réparatrice Aile 4, CHU Ibn Rochd de Casablanca, Maroc.
}

World Journal of Advanced Research and Reviews, 2021, 12(02), 001-005

Publication history: Received on 18 September 2021; revised on 21 October 2021; accepted on 23 October 2021

Article DOI: https://doi.org/10.30574/wjarr.2021.12.2.0537

\begin{abstract}
Neglected Achilles tendon ruptures are becoming more common. The etiologies are numerous, often complicating acute ruptures of the undiagnosed calcaneal tendon, whether by ignorance of the pathognomonic signs (loss of the physiological equine in prone position and Thomson's maneuver) or by erroneous diagnosis of partial rupture often induced by an ultrasound. Also, it can be due to an iterative ruptures or ruptures on a pathological tendon. The treatment is always performed by a surgery. However, techniques are numerous and depend on the indications. We describe in this work the surgical technique of repairing neglected Achilles tendon ruptures according to Bosworth, performed in the Department of Traumatology-Orthopedics and Reconstructive Surgery of the Ibn Rochd University Hospital Center in Casablanca, Morocco.
\end{abstract}

Keywords: Achilles tendon; Neglected ruptures; Surgical technique; Bosworth

\section{Introduction}

Calcaneal tendon rupture is defined as a loss of continuity of the calcaneal tendon without damage to the overlying integumentary planes. The criterion for the duration of the rupture of the Achilles tendon varies according to the authors, while that used in our study is 4 weeks between the rupture and the treatment [1].

The incidence of neglected Achilles tendon ruptures has been on the rise in recent years, along with the population gain from sports activities. Hypovascularization at the level of its insertion and its narrowed portion, aging and certain therapies (fluoroquinolones, corticosteroid infiltrations, etc.) can also explain the frequency of lesions of the calcaneal tendon [2-4].

Surgical treatment is almost always required in the absence of contraindications, but choosing the most appropriate procedure is often difficult due to tendon retraction and the loss of tissue created.

In this article, we will describe the Bosworth surgical technique described by the author of the same name [5] in the distribution and plasty of neglected Achilles tendon ruptures, used in the department of Traumatology-Orthopedics and Reconstructive Surgery. 4 from the Ibn Rochd University Hospital Center in Casablanca, Morocco.

\footnotetext{
${ }^{*}$ Corresponding author: Omar Fadili

Service de Traumatologie-Orthopédie et de Chirurgie Réparatrice Aile 4, CHU Ibn Rochd de Casablanca, Maroc. 


\section{Surgical technique}

\subsection{Anesthesia and installation of the patient}

The patient is installed in the prone position on an ordinary table with a block under the ipsilateral leg, a pneumatic tourniquet at the root of the lower limb inflated to $400 \mathrm{mmHg}$ after emptying the limb, under locoregional anesthesia (spinal anesthesia).

\subsection{Surgical approach}

A medial para-Achilles approach is recommended. After brushing and draping, leaving the lower limb free and movable, a posteromedial skin incision of about ten to fifteen centimeters is made. This prolonged proximal incision should expose the entire fascia of the triceps sural. Careful hemostasis is performed.

\subsection{Surgical technique}

After opening the skin, the Achilles tendon or mesotendon sheath is split lengthwise. The area of rupture is identified, showing the fibrous scar tissue (Figure 1). Next, we proceed to an end-to-end suture of both ends of the tendon through locked stitches (Figure 2). The fibrous zone is then resected in order to find a healthy tendon zone and then the loss of substance in maximal equine is measured. A $2 \mathrm{~cm}$ wide flap, more or less long depending on the extent of the rupture zone to be bridged, is taken from the thickness of the tricipital aponeurosis (Figure 3). Its lower pedicle is located about $2 \mathrm{~cm}$ above the rupture zone. Ideally, it is desirable not to take the entire thickness of the aponeurosis so as not to weaken the musculo-aponeurotic junction and to limit the pain phenomena secondary to the upper part of the calf (Figure 4). The removed flap is turned over and then sutured to the distal fragment with several separate stitches of slowly absorbing suture (strong Vicryl ${ }^{\circledR}$ type). The edges of the flap are sutured to the remaining calcaneal tendon (Figure 5). The sutures are made with less than $5^{\circ}$ of equinus by putting the foot on the table and allowing the aid to be released. All sutures are made using separate stitches distributed evenly and symmetrically in order to best distribute the stresses (Figure 6). [5]

\subsection{The variant of the Bosworth technique}

Several modifications of this technique have been proposed. The most widely used variant consists of taking the longest fascial strip up to $10-12 \mathrm{~cm}$ and the widest possible up to $3 \mathrm{~cm}$ but always remaining partial in thickness. After its removal, it is separated into three strands. Each of the inverted strands is passed through the lower end of the proximal fragment and then enters anteriorly of the distal fragment, exits either posteriorly or laterally to be sutured on itself. If the length of the sample is sufficient as well as depending on the size and the location of the loss of substance, we suture the ends of the different strands again on the proximal fragment of the calcaneal tendon. This modification with back and forth suturing of the different strands makes it possible to fill the defect by reconstructing a real tendon [6].

\section{Iconography}

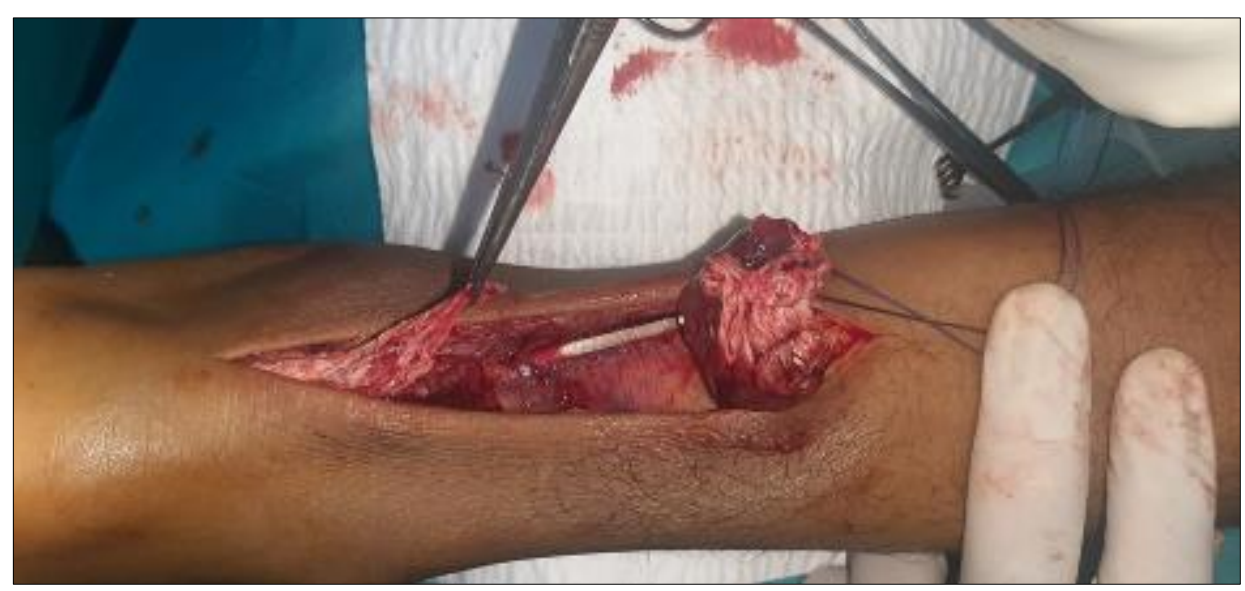

Figure 1 Pathological appearance of the Achilles tendon with jagged edges 


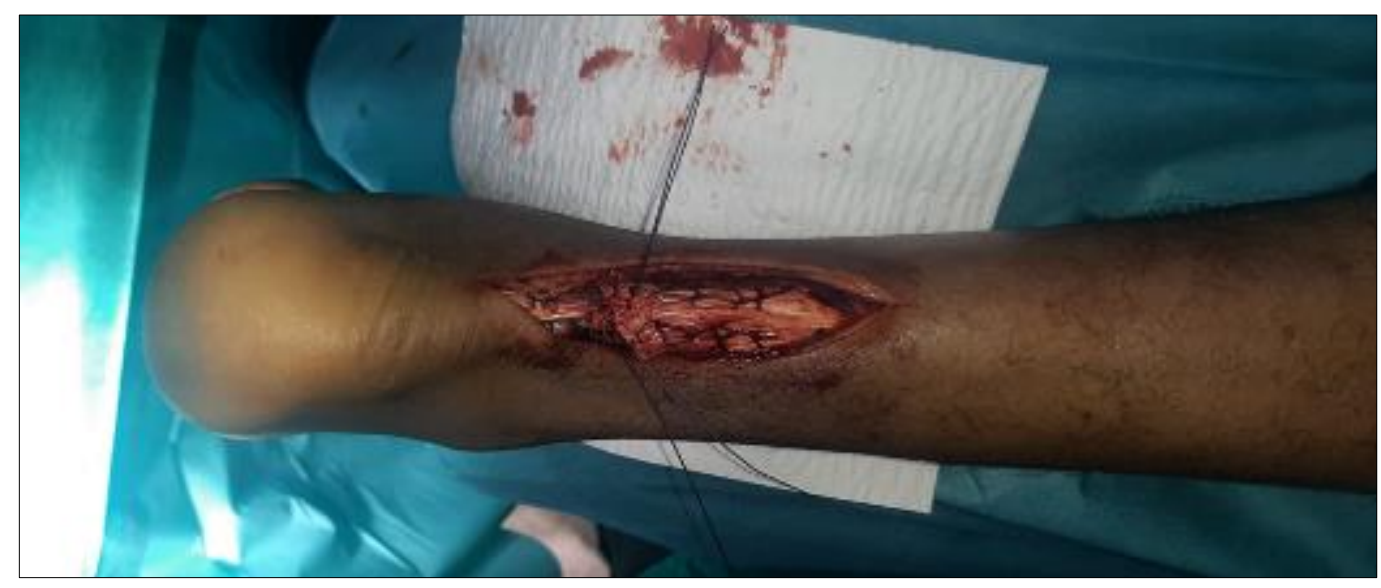

Figure 2 End-to-end suture of the Achilles tendon with locked stitches

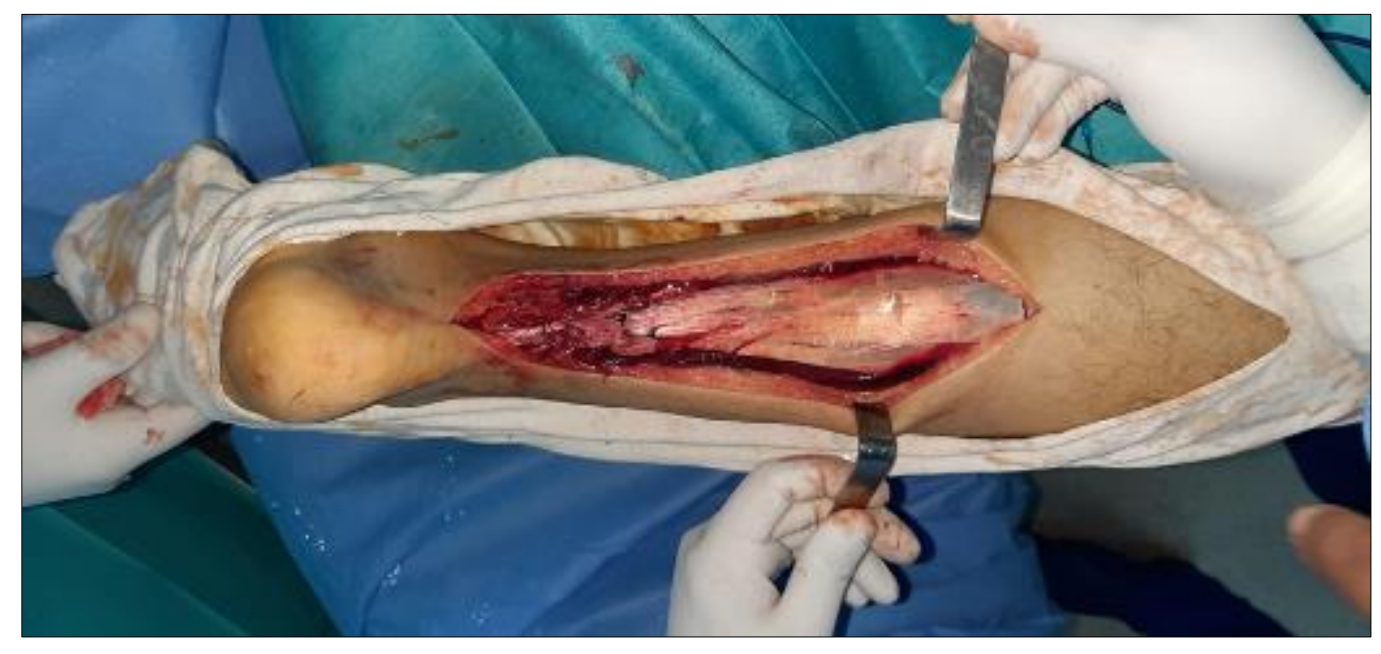

Figure 3 Widening of the incision for harvesting the tricipital fascia

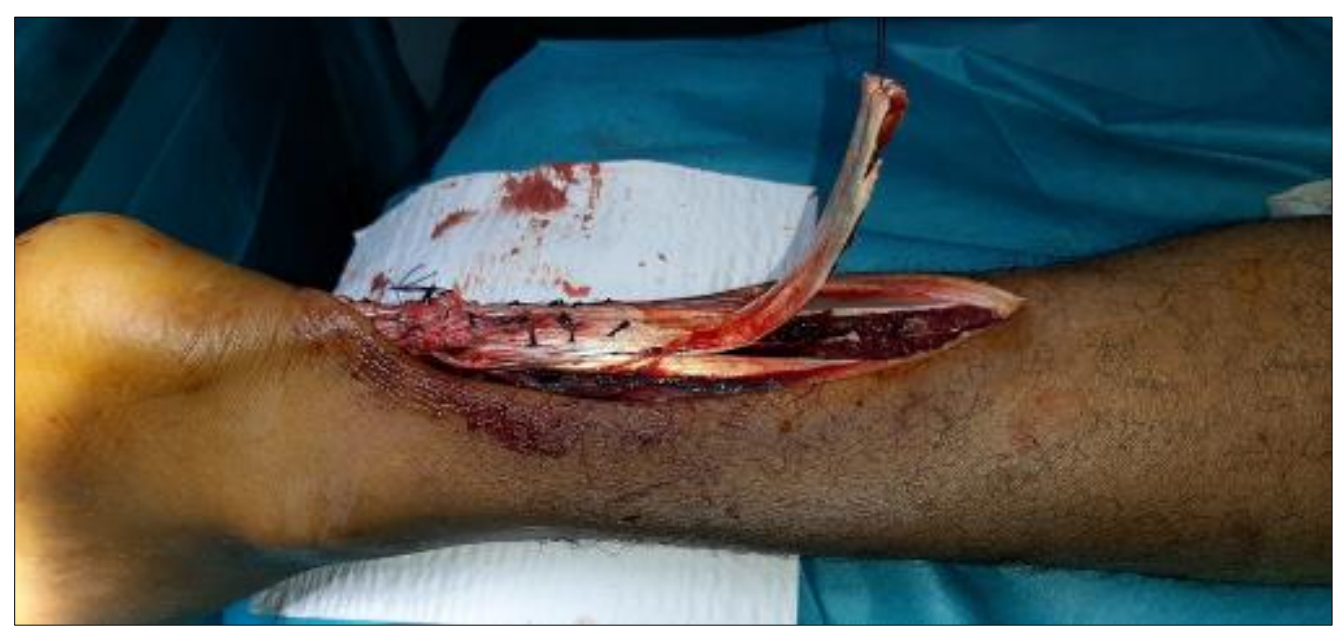

Figure 4 Detachment of the harvested tricipital fascia and preparation for an overturn 


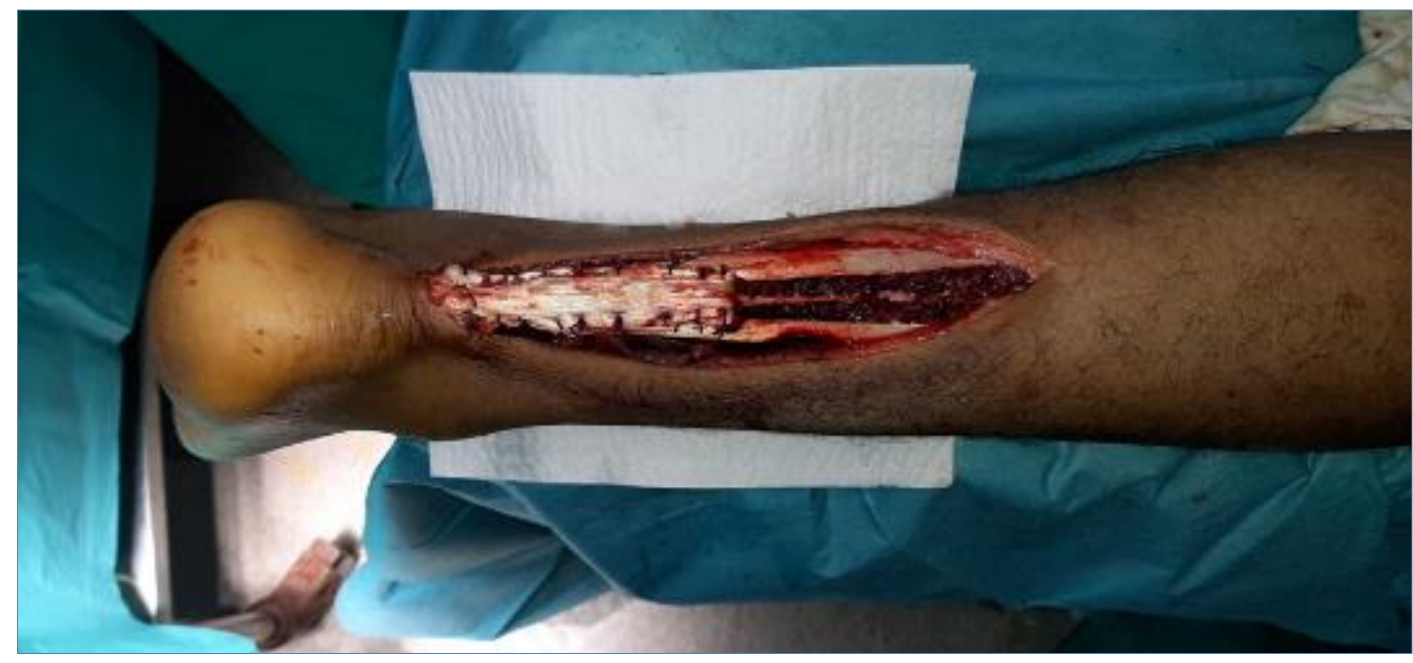

Figure 5 Suture of the flap to the distal fragment and lateral parts of the Achilles tendon

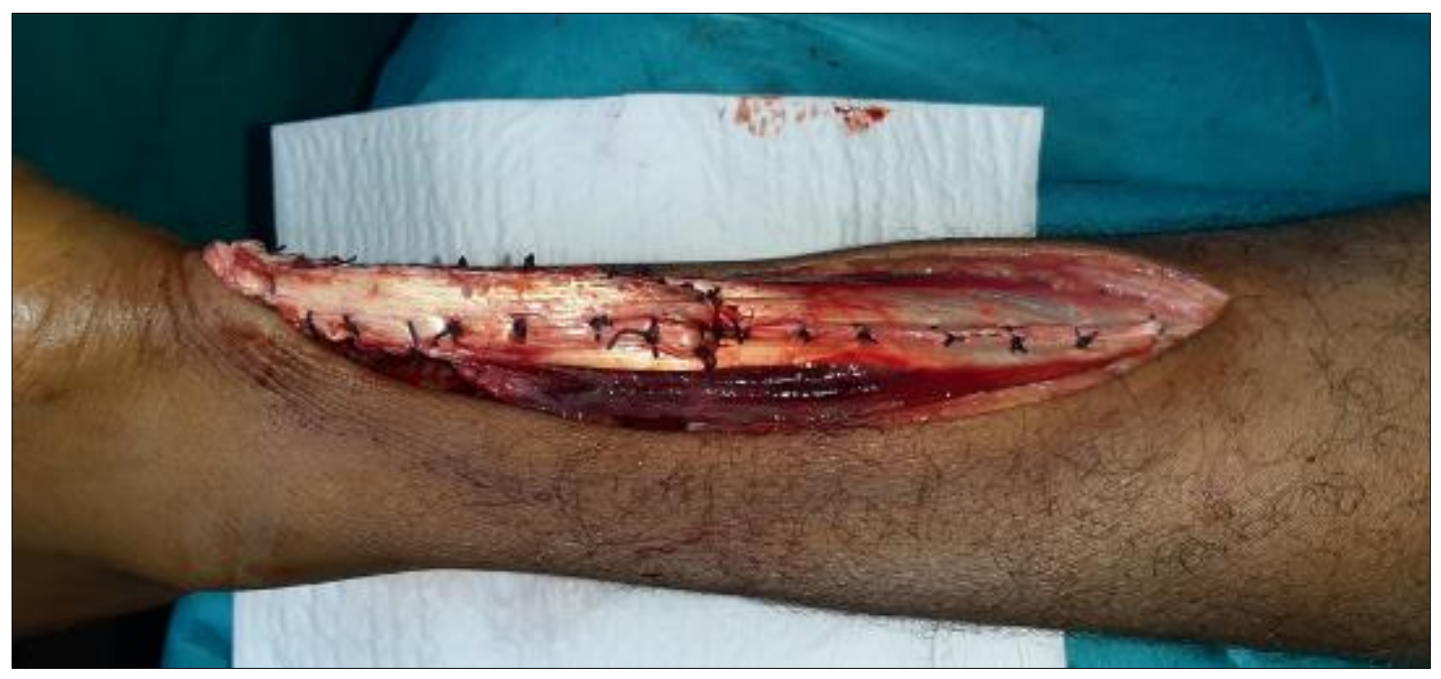

Figure 6 Final appearance of Achilles tendon plasty according to Bosworth

\section{Conclusion}

Neglected heel tendon ruptures represent a difficult surgical problem due to tendon retraction and loss of substance. They are more and more frequent due to the considerable development of sports activities, the increase in their intensity and the lack of means of prevention. whose knowledge of surgical repair techniques is of particular interest.

\section{Compliance with ethical standards}

\section{Conflict of interest}

None

\section{Statement of ethical approval}

The present research work does not contain any studies performed on animals/humans subjects by any of the authors.

\section{Statement of informed consent}

Informed consent was obtained from all individual participants included in the study. 


\section{References}

[1] Guillet R, Genety J, Brunet-Guedj E, Brazas J. Rruptures et plaies du tendon d'Achille; Encyclopédie Médicochirurgicale, Appareil locomoteur, fasc. 1993; 14090: A-10.

[2] Holmes GB, Lin J. Etiologic factors associated with symptomatic achilles tendinopathy; Foot Ankle Int. 2006 Nov; 27(11): 952-9.

[3] Graf J, Scheider U, Niethard FU. The microcirculation of the Achille tendon and importance of the paratendon. A study with a new method; Handchir. Microchir. Plast. Chir. 1990; 22(3): 163-166.

[4] Mahler F, Fritschy D. Le point sur le rôle des injections locales de corticostéroïdes dans les ruptures d'Achille ; Médecine et hygiène. 1993; 51: 1888.

[5] Bosworth DM. Repair of detects in the tendo Achillis; Journal of Bone and Joint Surgery. 1956; 38 - A: 111 -114.

[6] Mann RA, Holmes GB Jr, Seale KS, et al. Chronic rupture of the Achilles tendon:a new technique of repair; Journal of Bone Joint Surg. 1991; 73: 214-9. 